\title{
Maximum Power Point Tracking for Stand-Alone Solar Photovoltaic System Connected to Battery Energy Storage Using Intelligent Control
}

\author{
Samah M. Saleem, Helmy M. El Zoghby* and Soliman M. Sharaf
}

\author{
Department of Electrical Power and Machines, Faculty of Engineering \\ Helwan University, Cairo, Egypt
}

E-mail: Mgaflana2011@hotmail.com; helmy_028123288@yahoo.com; soliman_sharaf@yahoo.com

*Corresponding author details: Helmy M. EI Zoghby; helmy_028123288@yahoo.com

\begin{abstract}
This paper introduced modeling and simulation results of an isolated solar photovoltaic system with lead-acid battery. The system is operated at maximum power point tracking (MPPT) using MATLAB/Simulink environment. The proposed controllers used in this paper are proportional - integral (PI) controller, fuzzy logic controller (FLC) and Adaptive Neuro Fuzzy Inference System (ANFIS) controllers. The proposed controllers are used for controlling dc-dc converter. All simulation results are recorded and compared with each other using the conventional and intelligent controllers.
\end{abstract}

Keywords: Adaptive Neuro Fuzzy Inference System (ANFIS); Maximum Power Point Tracking (MPPT); PV System; Battery; PI controller; Fuzzy Logic Control (FLC)

\section{INTRODUCTION}

Due to a massive consumption of fossil fuels to achieve the energy demands, its increasing prices and increasing pollution on our environment, existing new electrical resources is a must. There are different renewable energy resources such as solar, wind, hydropower. Solar energy is the most important one as it shows more advantages rather than other sources. It is clean, simple and has low maintenance costs, ease of installation, flexible, does not require continuous maintenance or any moving mechanical parts.

On other hand photovoltaic system has some drawbacks the main one is energy extracted from this system is intermittence, relies on weather conditions and has high installation cost.

As the photovoltaic system depends on sunlight to generate electricity. This limits its system to only day time when sunlight is available. To use solar energy at any time of the day and night, battery energy storage is the most suitable solution.
Therefore, solar PV charge controller is the main part in this solution.

The solar PV charge controller is commonly used in standalone system applications such as street lighting, telecommunication base stations, etc. A Solar PV MPPT connected to charge controller includes a MPPT tracker. The MPPT tracks the maximum power from the PV panel and gives it to the battery charge controller. The charge controller charges the battery through three stages to avoid damaging the battery caused by excessive charging and overheat.

As maximum power point (MPP) depends on array temperature and solar irradiance. The dc-dc converter tracks MPP of PV module by many methods for tracking such as PI controller, Fuzzy Logic Control (FLC) and Adaptive Neuro Fuzzy Inference System (ANFIS) controllers.

Those methods are tested in steady state performance using MATLAB/Simulink.

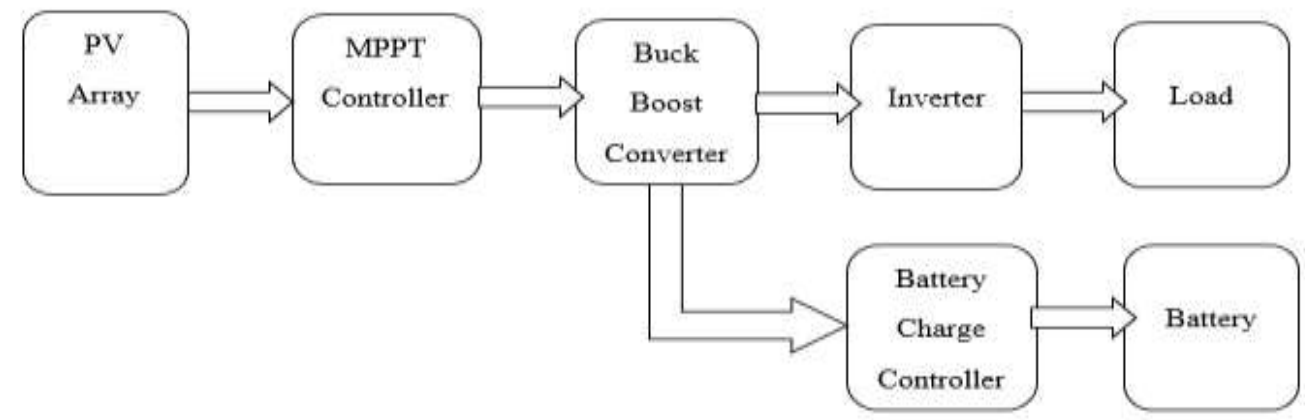

FIGURE 1: Block diagram of stand-alone PV system connected to battery 
Using MPPT between the array and load to extract the available array maximum power output and also to match the impedance of the electrical load to the maximum power output of the PV array. Figure 1 shows the general block diagram of the standalone solar PV system. The block diagram consists of PV array and its MPPT controller, bidirectional DC-DC converter, battery and its charge controller inverter that supplies AC load. Batteries are used for energy storage and is used as an alternative source in many stand-alone PV systems. PV panels are connected in series to obtain the desired increase in DC voltage, such as 12,21 , or $48 \mathrm{~V}$. The charge controller regulates the current output and prevents the voltage level from exceeding the maximum value for charging the batteries.
During the sunshine hours, the load is supplied with DC power while simultaneously charging the battery. Bidirectional DC-DC converter in Figure 1 is used to perform the process of power transfer between two dc sources in either direction. They are widely used in various applications for interfacing the battery storage system. Battery bank sizing depends on duration of an uninterrupted power supply to the load when there is less radiation from the sun. The battery bank also consumes a 20-30\% power loss due to heat during its operation, which also must be taken into consideration. When designing a solar PV system with a battery backup, it must be related to the suitable location for the battery racks and room ventilation.

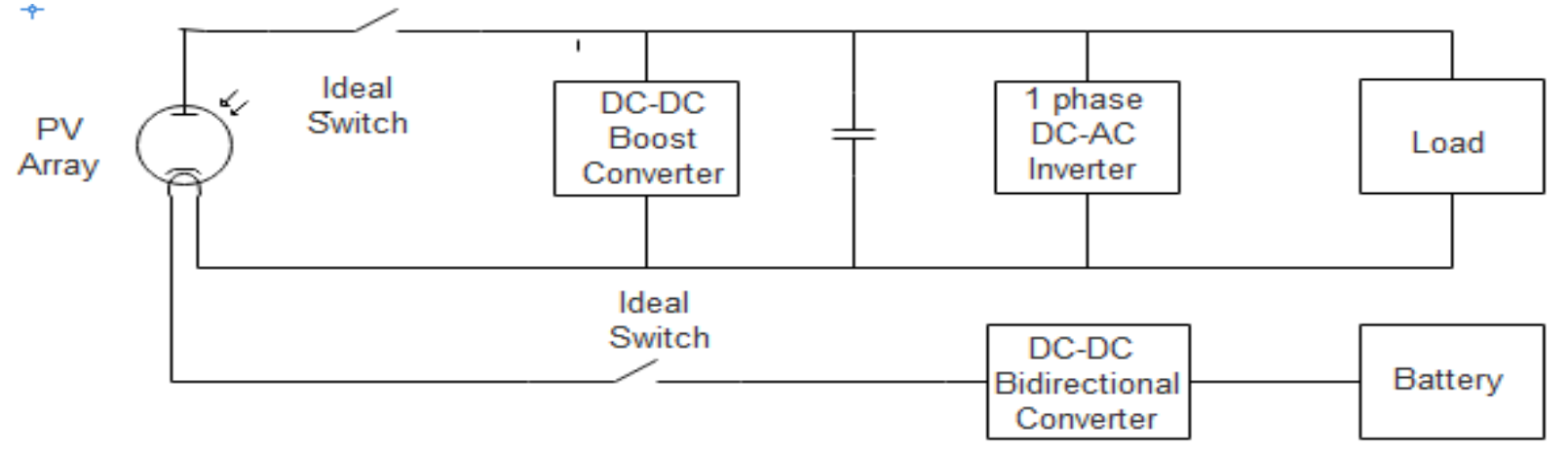

FIGURE 2: Block diagram of PV battery system

From Figure 2 it can be seen that the PV voltage source has immediately next to it a boost converter stage powered by MPPT controller which will step up the PV voltage to the desired DC bus voltage extracting maximum power from the PV system at every instance of operation. It is then followed by couple of IGBTs and a battery acting as a secondary source.

Batteries are used to store this power in case the load demand is less. Battery banks when used without a bidirectional converter are required to be in large numbers, but using many batteries is not economical and convenient as even one cell failing can disrupt the entire current flow. Transformer based isolated bidirectional converters are expensive and also have greater power loss due to use of many switches. The battery used in this system is a LeadAcid battery because of its low cost and long life. PV array output is boosted to the required value of the load. The battery is connected via a dc-dc bidirectional converter. The dc-dc converter uses IGBT for its fast-switching speed and low output impedance as we can see in Figure 2.

\section{PV SYSTEM CONNECTED TO BATTERY STORAGE USING BIDIRECTIONAL DC-DC CONVERTER}

A bidirectional DC-DC converter is an important part of standalone solar PV systems for interfacing the battery storage system. The circuit is operated in such a way that one switch and one coupled inductor are used for step-up operation to boost the voltage of the battery to match the high voltage dc bus. The other switch, remaining diode and simple inductor are used for step down operation to charge the battery from the PV array. The high efficiency of the converter is achieved by optimizing components used for each step.

The bidirectional DC-DC converter with high power rate plays a main role in power storage systems, while it converts DC power for the storage battery. The Bidirectional DC-DC converter operates either as a buck or as boost converter at any instance. It works as a buck converter for charging the battery whereas it operates as a boost converter while the battery discharges power to the load.

$$
\mathrm{PV}+
$$

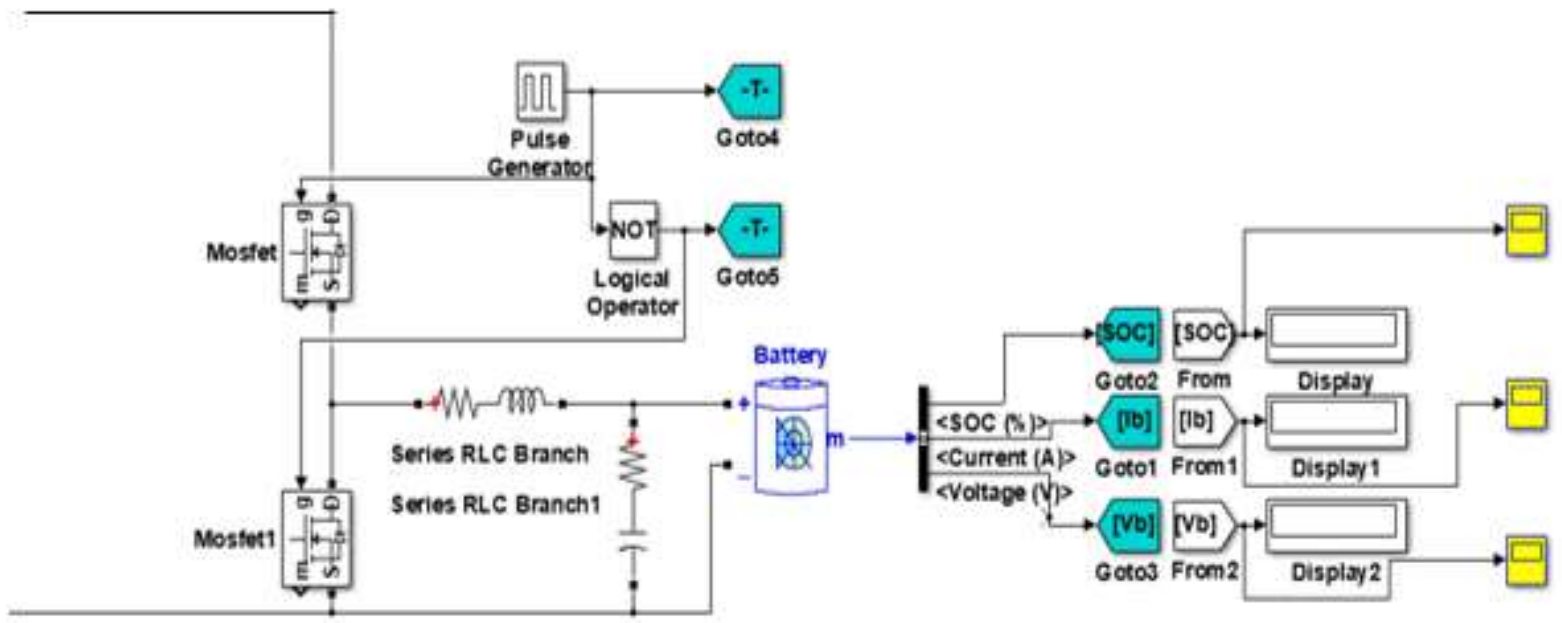


From Figure 3 it can be seen that the Bidirectional DC-DC converter operation is carried out through these two IGBTs which are controlled by two different controllers One controller provides the control signal for boost operation and the other provides the control signal for buck operation. It operates bidirectional DC-DC converter that is used to perform the process of power transfer between two dc sources in two directions. They are commonly used in various applications.

Since the PV array voltage is higher than the battery voltage, a buck topology is commonly chosen for solar PV charge controller application. The buck converter operates as a regulator to step down the input voltage from the PV array while maintaining its power delivery to charge the battery. This is achieved by stepping down the input voltage and increasing the output current delivered to the battery. The buck converter circuit consists of a MOSFET switching device, a high-power inductor, diode, and an input and output capacitor as shown in Figure 2. The reverse blocking diode D1 is used to prevent the reverse flow of current back to the PV array from the battery during night time. The output voltage of the buck converter can be determined by the ratio between Vout the output voltage and Vin the input voltage of buck converter where $\mathrm{D}$ is the duty cycle of the PWM signal.

$$
\mathrm{D}=\frac{\mathrm{V}_{\mathrm{o}}}{\mathrm{V}_{\mathrm{in}}}
$$

The duty cycle can also set the active input resistance of the PV array source where MPPT can be realized. The effective input resistance $R_{\text {in }}$ of the source can be determined in where $\mathrm{R}_{\text {load }}$ is the load or battery resistance.

$$
\mathrm{R}_{\text {in }}=\frac{\mathrm{R}_{\text {load }}}{\mathrm{D}}
$$

The buck converter inductor ripple current peak to peak magnitude under steady-state condition can be determined in where $\mathrm{V}_{\text {in }}$ is the input voltage of the PV array, $f_{s w}$ is the switching frequency and $\mathrm{L}$ is the inductor value.

$$
\Delta I_{L}=\frac{\mathrm{V}_{\text {in }} D(1-D)}{f_{s w} L}
$$

Similarly, the buck converter output capacitor ripple voltage peak to peak magnitude under steady-state condition can be determined in the following equation.

$$
\Delta V_{c}=\frac{\mathrm{V}_{\mathrm{in}} D(1-D)}{8 L c f_{s w}^{2}}
$$

\section{CHARGE CONTROLLER}

A charge controller limits the electric current rate is added to or pulled from batteries. It prevents overcharging and overvoltage, which can reduce battery efficiency or lifetime. To protect battery life, charge controller may prevent battery from deep discharging by controlling it. To keep batteries working optimally, it must prevent overcharging (by disconnecting solar panels, when batteries are full) and to prevent too deep discharge (by disconnecting the load when necessary) as the battery is very expensive component of the solar system.
A solar charge controller regulates the voltage and current that is coming from the solar panels to the battery so it is controlling its charging and discharging to protect it from damage. The PV panel that is used produce about 16 to 21 volts, so if there is no regulation, the batteries will be damaged from overcharging, as the battery is fully charged causing electrolyte loss and internal heating.

There are two types of charge controllers of solar power systems pulse width modulation (PWM) and maximum power point tracking (MPPT). Both of them adjust charging rates depending on the battery's maximum capacity by monitoring the battery temperature to prevent overheating. Some larger systems may have a bidirectional inverter that can also charge the batteries from an AC source. This inverter is also called an invertercharger.

There are also very cheap solar charge controllers that only passes through the solar PV voltage and shuts it off when the batteries are full. Both PWM and MPPT solar charge controllers can have three charging stages (bulk, absorption and float stages) can help the battery to get long lifetime.

\section{(a) PULSE WIDTH MODULATION (PWM) CHARGE CONTROLLER}

Pulse width modulation (PWM) charge controller is the most effective means to achieve constant voltage battery charging by adjusting the duty ratio of the switches (MOSFET).

In PWM charge controller, the current of the PV panel gradually decreased according to the battery's condition and recharging needs. When a battery voltage reaches the regulation set point, the PWM algorithm slowly reduces the charging current to avoid battery heating. The voltage of the PV array will be pulled down also to near that of the battery.

PWM system has many advantages: It has High charging efficiency, it can reduce battery overheating and minimizes stress on the battery, so it gives Long battery life.

\section{(b) MAXIMUM POWER POINT TRACKING (MPPT) CHARGE CONTROLLER}

Using a lead acid battery charge controller for PV power with maximum power point tracking is safer and gives high performance. It is more advanced and more expensive. It has several advantages over the PWM charge controller. It is 30 to $40 \%$ more efficient at low temperature. The MPPT is based on buck converter circuit. It steps the higher solar panel voltage down to the charging voltage of the battery. However, the converter is fitted with filter to smooth out power flow in order to avoid voltage ripples.

The MPPT charge controller is a DC-DC step down transformer that can transform power from a higher voltage to power at a lower voltage. So, the amount of power does not change, therefore, if the output voltage is lower than the input voltage, the output current will be higher than the input current, so that the product $\mathrm{P}=\mathrm{VI}$ remains constant.

In Figure 4 a graph showing current and voltage curves during three charge stages bulk, absorption and float stages. 


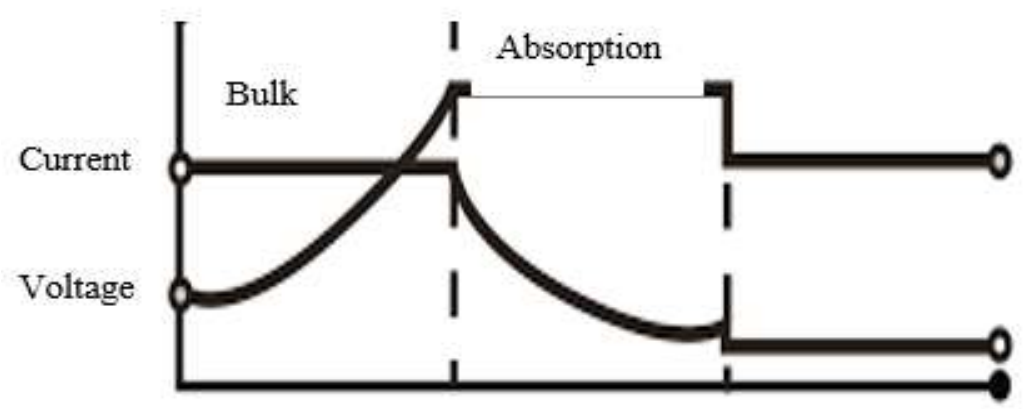

FIGURE 4: Current and Voltage curves during battery charging stages

It is so important to calculate battery capacity for the solar system to get maximum power generating efficiency from the PV modules.

Batteries needed $(\mathrm{Ah})=$ Daily consumption $(\mathrm{Ah}) *$ Back up days*Annual correction factory 1.15/DOD (\%)

Using Annual correction factory as the fact that batteries will not be new forever and their maximum power will be less over the years.

In this case using $150 \mathrm{~W} 12 \mathrm{~V}$ PV array that can produce $8 \mathrm{~A}$ current (according to manufactures and models) it has battery with 225Ah, max. Power of battery is $12 v^{*} 225=2700$ Wh that means PV array of 28 modules charge battery within hour with charger capacity of $12 \mathrm{v}$ $225 \mathrm{~A}$ to generate huge current and it costs a lot of cost of PV arrays.
So, we need only $100 \mathrm{Ah}$ every day with 3 days back up time and $80 \%$ DOD.

Battery needed $=100 * 3 * 1.15 / 0.8=431 \mathrm{Ah}$

DOD: Depth of Discharge

\section{MPPT USING PI CONTROLLER TECHNIQUE}

Maximum power point tracking (MPPT) controller for a (PV) system is presented in Figure 5. The proposed MPPT controller was designed to extract the maximum of power from the PV-module and reduce the oscillations. To achieve this goal, a different MPPT methods was used to drive a DC-DC Boost converter which was used to link the $\mathrm{PV}$-module and a resistive load capable of acting on the duty cycle of the DC-DC converter in order to be able to track the MPP of the PV system.

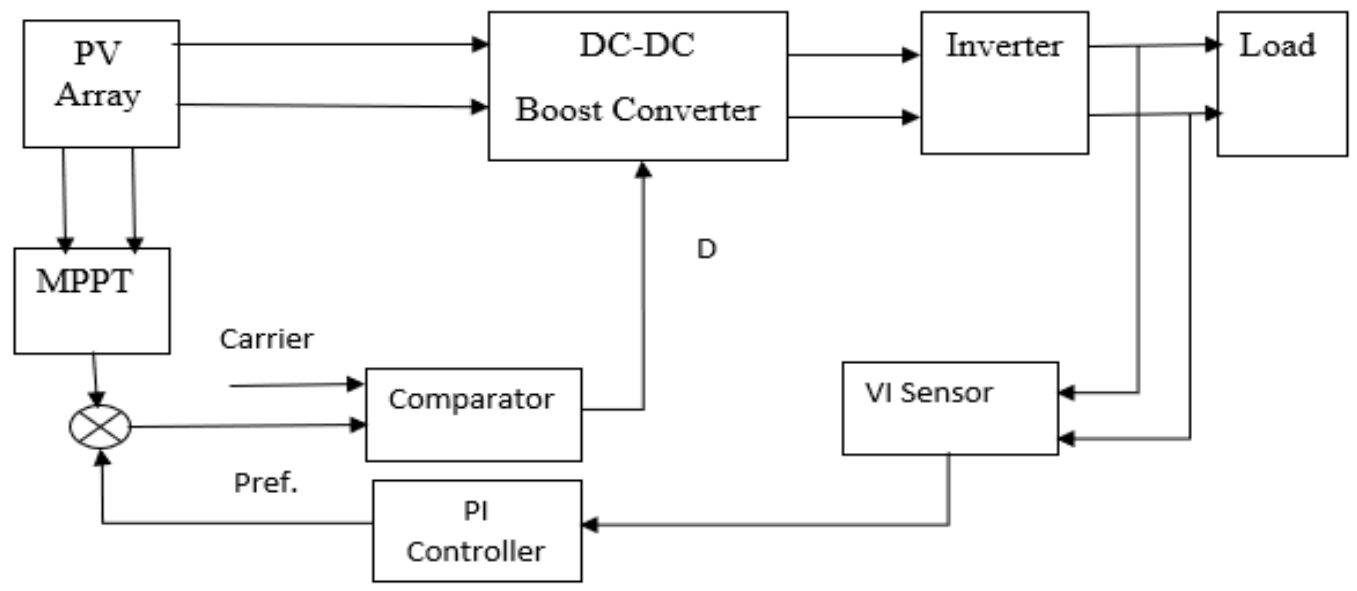

FIGURE 5: PV system with resistive load and PI controller

This study represents modeling and simulation of standalone PV system. The work has been carried out on a 150 W PV array. The main structure of this PV array system consists of PV Array, DC- DC boost converter, single phase Inverter, resistive load and PWM controller for inverter and for DC-DC boost converter and PID controller. It is necessary to implement PID controller to track changes and maximize the power extraction from the PV-module by comparing reference and actual power of PV module. PI controller maintains zero output error between actual and set point/desired output power. It integrates the error during a period of time until error value reaches zero. Then PWM comparator is used to compare the reference power of control signal with a carrier saw tooth signal to obtain the PWM control signal in the MOSFET transistor gate. Overall system is simulated with MATLAB/Simulink.

\section{MPPT USING FUZZY LOGIC TECHNIQUE}

It is working with accurate inputs, without needing to a mathematical model and it used for duty cycle controlling of the DC-DC boost converter to reach MPP. The main role of the fuzzy logic controller is to measure the power of PV array at certain radiation and temperature.
This value is considered to be the input of the fuzzy controller. The output of a fuzzy controller represents the duty cycle of the DC-DC converter.

Fuzzy logic controller consists of three stages: fuzzification, rule base lookup table, and defuzzification as it is shown in Figure 7. During fuzzification, numerical input variables are converted into linguistic variables based on a membership function. In this case, five fuzzy levels are used: NB (negative big), NS (negative small), ZE (zero), PS (positive small), and PB (positive big).

The inputs to a MPPT fuzzy logic controller are usually an error $\mathrm{E}$ and a change in error $\Delta \mathrm{E}$. The user has the flexibility of choosing how to compute $\mathrm{E}$ and $\Delta \mathrm{E}$. Since $\mathrm{dP} / \mathrm{dV}$ vanishes at the MPP. By calculate the following

$$
\begin{aligned}
& \mathrm{E}(\mathrm{n})=\frac{P(n)-P(n-1)}{V(n)-V(n-1)} \\
& \Delta E(n)=E(n)-E(n-1)
\end{aligned}
$$


Once $\mathrm{E}$ and $\Delta \mathrm{E}$ are calculated and converted to the linguistic variables, the fuzzy logic controller output, which is typically a change in duty ratio $\Delta \mathrm{D}$ of the power converter or $\Delta \mathrm{P}$ the change in power, can be looked up in a rule base table such as Table 1 .
In the defuzzification stage, the fuzzy logic controller output is converted from a linguistic variable to a numerical variable still using a membership function. This provides an analog signal that will control the power converter to the MPP, MPPT fuzzy logic controllers have been shown to perform well under varying atmospheric conditions. The fuzzy logic controller's main advantage that is fast converge and more stable.

TABLE 1: Fuzzy linguistic variables

\begin{tabular}{|c|c|c|c|c|c|}
\hline$\Delta \mathrm{E}$ & $\mathrm{NB}$ & $\mathrm{NS}$ & $\mathrm{ZE}$ & $\mathrm{PS}$ & $\mathrm{PB}$ \\
\hline NB & ZE & ZE & NB & NB & NB \\
\hline NS & ZE & ZE & NS & NS & NS \\
\hline ZE & NS & ZE & ZE & ZE & PS \\
\hline PS & PS & PS & PS & ZE & ZE \\
\hline PB & PB & PB & PB & ZE & ZE \\
\hline
\end{tabular}

The system configuration is shown in Figure 6 consists of the PV system generates power then converted by boost converter to adapt to battery and R load characteristics.
The duty cycle value of the boost converter is adjusted by the voltage and current of the controlled photovoltaic by MPPT based on Fuzzy Logic Controller (FLC) to get maximum power.

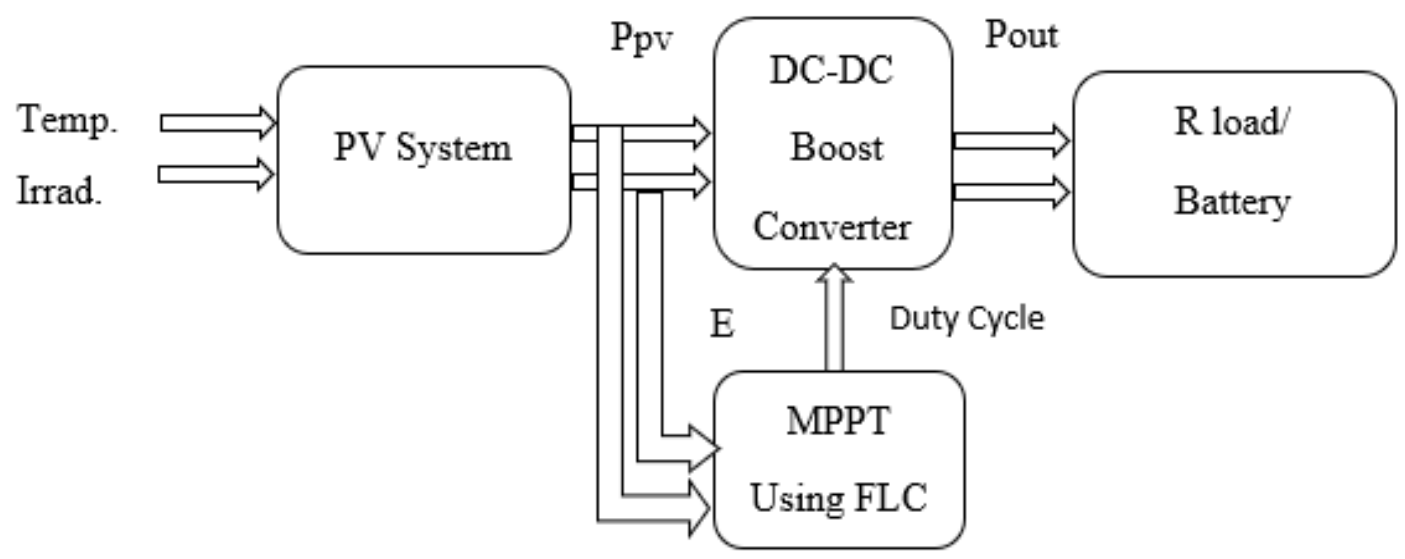

$\Delta \mathrm{E}$

FIGURE 6: Block diagram of MPPT using fuzzy logic controller and battery

The error $(\mathrm{e}(\mathrm{k}))$ and change in error $(\Delta \mathrm{e}(\mathrm{k}))$ are calculated from above equations (5), (6). The error is the difference between the boost output power and reference power, while the change in error is the difference between the present error and pervious error.
The variables and rule base table describe the control algorithm. The rule base depends on the error signal e(k), the change in error signal $\Delta \mathrm{e}(\mathrm{k})$, and switching duty-cycle signal.

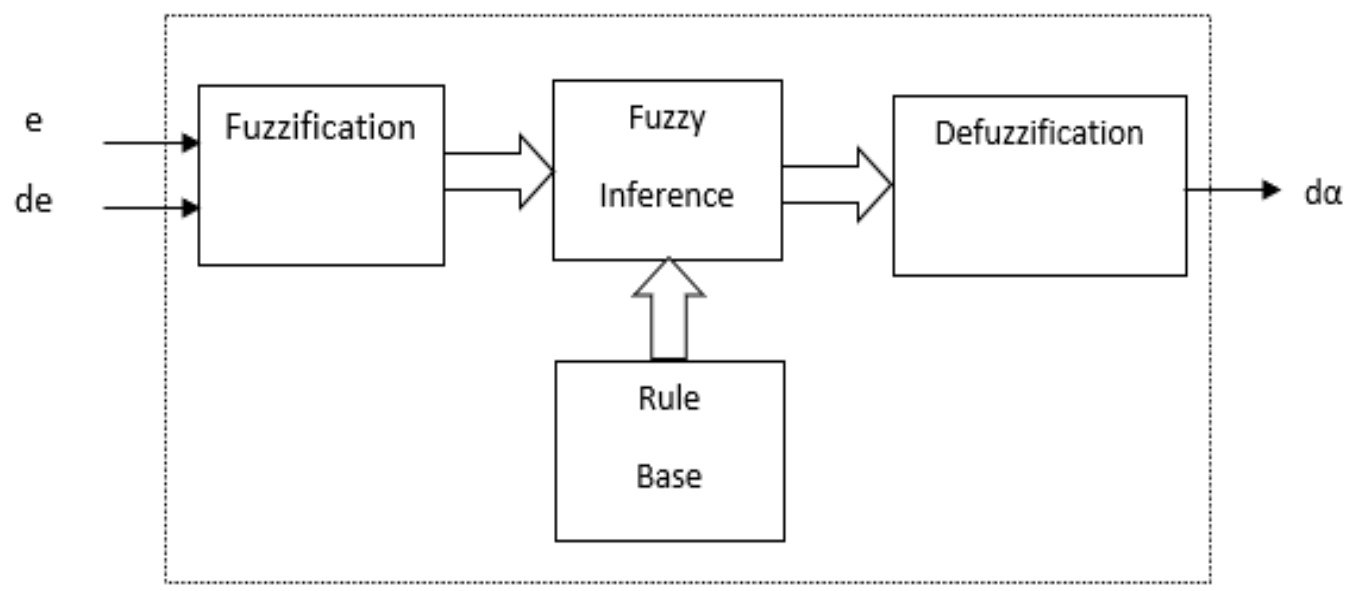

FIGURE 7: Fuzzy logic controller block diagram 
A continuous tracking of the MPP of the PV array, by adjusting of a boost duty cycle, got via the fuzzy logic based MPPT control, according to the variation of the two following inputs e and $\Delta \mathrm{e}$ as it is shown in Figure 8.
The PV power difference $(\Delta \mathrm{P})$ will be increased or decreased in the positive or in negative direction with a small or a large value until it approximates the MPP and the error almost equals zero.

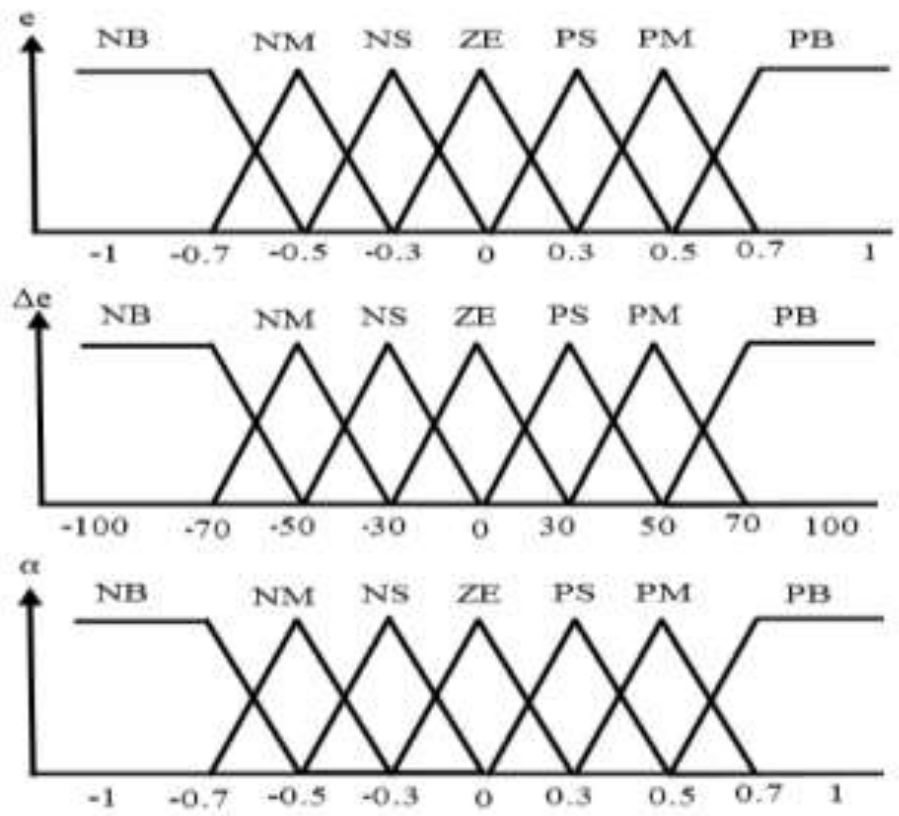

FIGURE 8: Membership functions of the input and output

The fuzzy inference step where as the defuzzification computes the incremental change duty cycle $\Delta \alpha$ :

$$
\Delta \alpha=\frac{\sum_{\mathrm{i}=1}^{\mathrm{n}}\left(\mathrm{d} \alpha_{\mathrm{i}}+\mathrm{u}_{\mathrm{i}}\right)}{\sum_{\mathrm{i}=1}^{\mathrm{n}} \mathrm{u}_{\mathrm{i}}}
$$

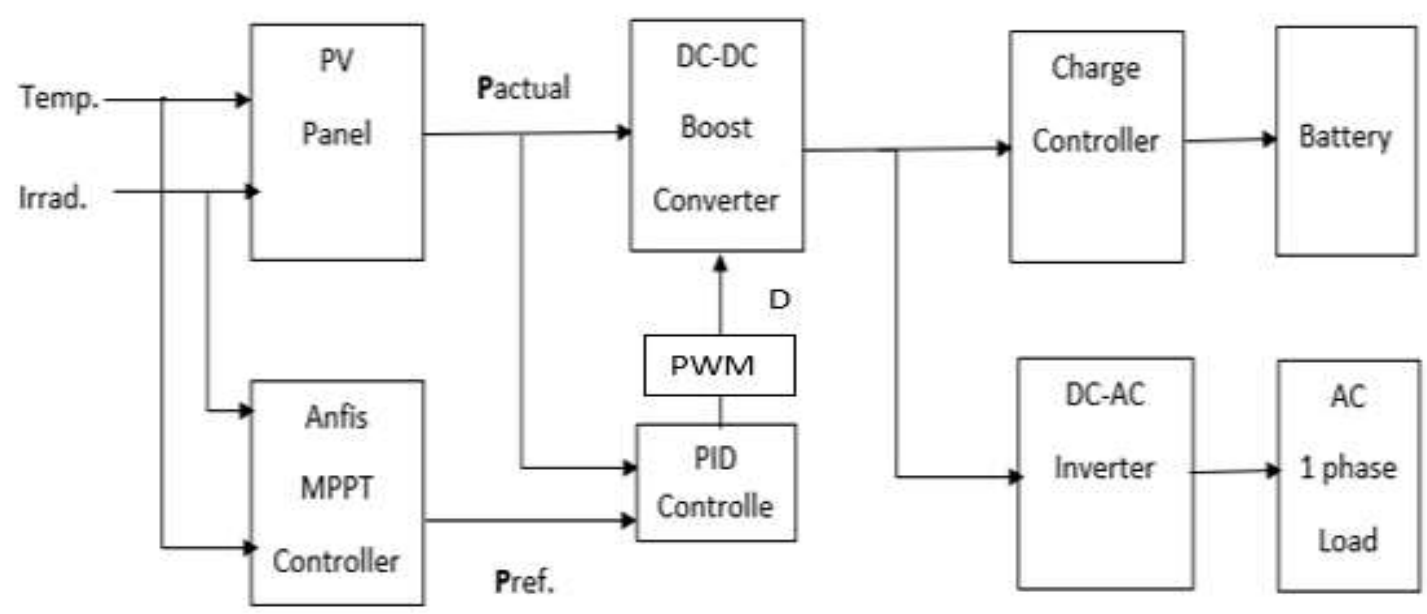

FIGURE 9: Block diagram of MPPT using Anfis controller and battery

As we can see in Figure 9 the Anfis block diagram consists of PV panel, DC-DC boost converter controller, inverter, AC load, charge controller and its battery.

Anfis tracks the maximum power point by controlling the duty ratio of the boost converter by adjusting the power of the PV panel. The duty ratio is changed according to the solar irradiance and the temperature. The Anfis algorithm is trained to generate the maximum power point according to the appropriate solar irradiance and the temperature.

The output of Anfis is a reference signal which can be compared with the instantaneous power to generate the control signal needed to drive the solar panel to MPP through a PI controller.

\section{MPPT USING ADAPTIVE NEURO FUZZY INFERENCE SYSTEM(ANFIS) TECHNIQUE}

Anfis is a hybrid scheme for solving complex problems, belongs to adaptive neural networks that offer a combination of learning, adaptability, nonlinear and time variant problem solving of ANN and considerable concepts of fuzzy sets theory. 
That signal is given to the PWM generator and control the duty cycle of DC-DC boost converter to adjust the operating point of the PV module.

DC-DC boost converter is designed to be placed between solar PV module and load to transfer maximum power to load by changing duty cycle.
The PV cell temperature varies from $10^{\circ} \mathrm{C}$ to $70^{\circ} \mathrm{C}$ and the solar irradiance varies from 50 to $1200 \mathrm{~W} / \mathrm{m} 2$. By varying these two inputs data will be simulated.

The data set for temperature and irradiation is continuously varying. So, data is trained using ANFIS technique and the optimal power supplied by PV is recorded as shown in Figure 10.

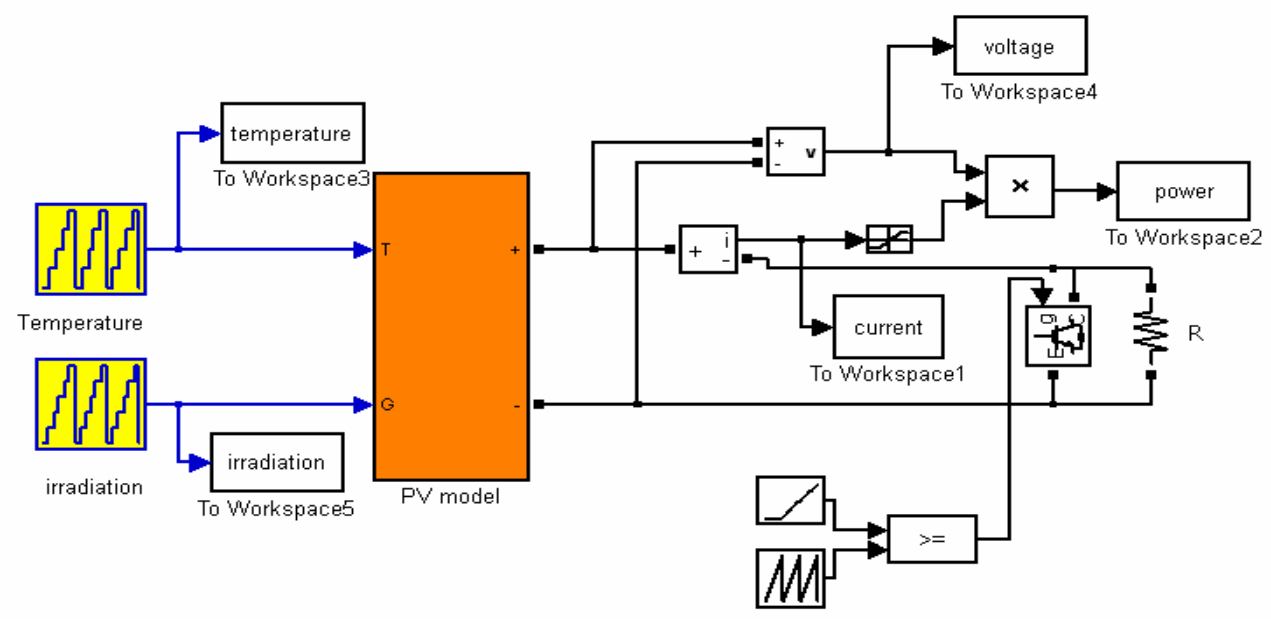

FIGURE 10: Training of ANFIS using MATLAB Simulink

\section{SIMULATION RESULTS}

The proposed PID controller, FLC and ANFIS controller are tested under SIMULINK (MATLAB) connected to stand alone PV array as shown in Figure 12.
In this case, changes in solar radiation are applied to check the robustness and stability of the proposed controllers.

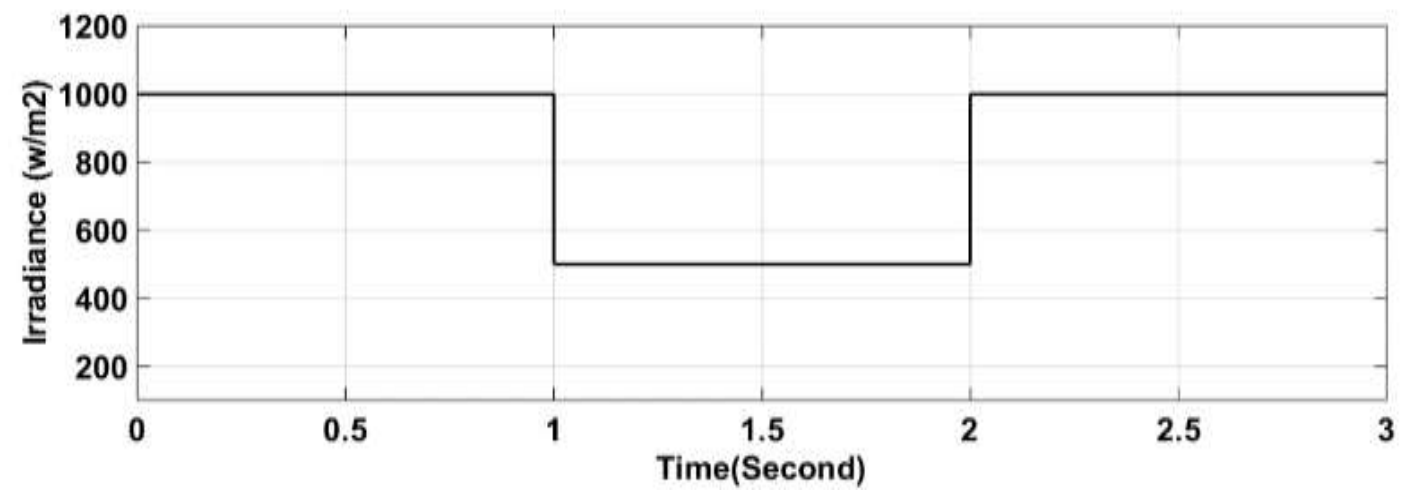

FIGURE 11: Irradiance pattern

In this case the temperature is constant and equal to $25^{\circ}$ ,site irradiation starting with $1000 \mathrm{~W} / \mathrm{m} 2$ then it changes to $500 \mathrm{~W} / \mathrm{m}^{2}$ after one second then it returns back to 1000 $\mathrm{W} / \mathrm{m}^{2}$ for one second also as illustrated in Figure 11.
So, we can study battery voltage, battery current, power, and Soc (\%) by using PID controller, FL controller and Anfis controller.

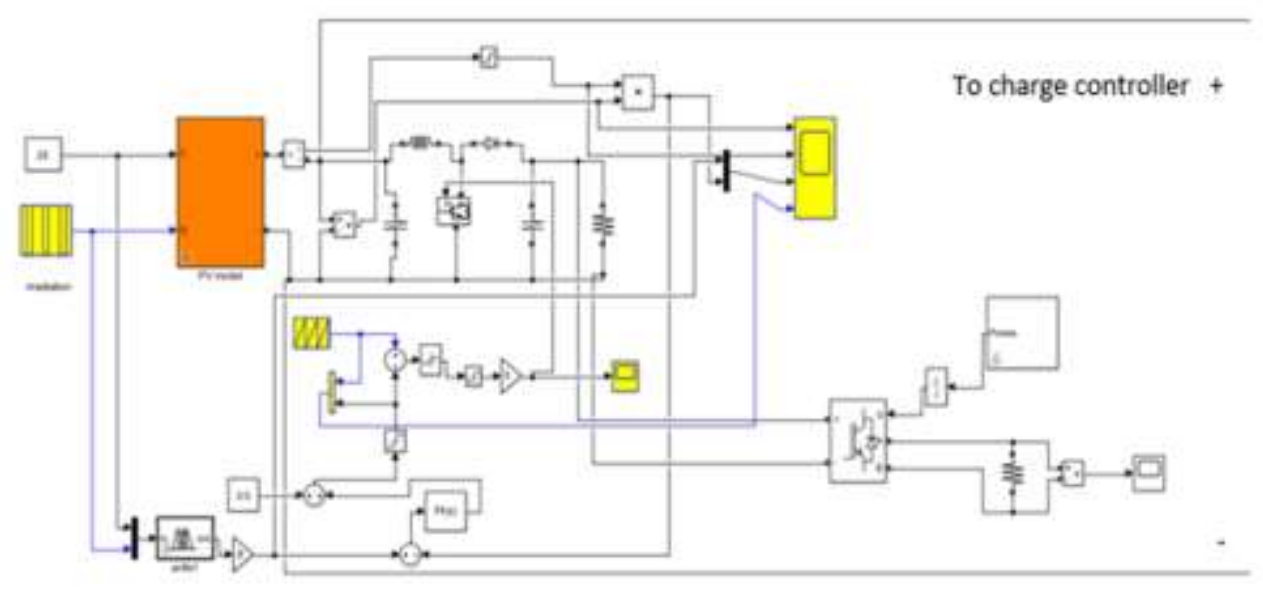

FIGURE 12: Stand-alone PV Array connected to battery using Anfis controller 


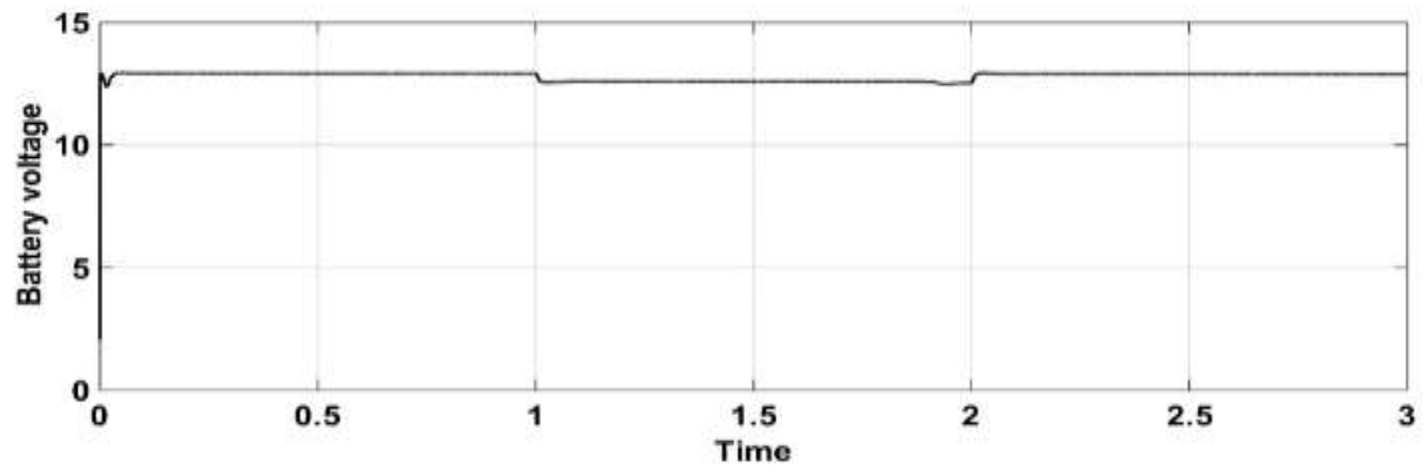

FIGURE 13: Battery charging voltage by using PID Controller

As we can see in Figure13, battery voltage is about $12 \mathrm{~V}$ by using PI controller during battery charging but it becomes less when irradiance equals (500) $\mathrm{W} / \mathrm{m}^{2}$. The MPPT using PID Controller method is a bit difficult to execute and it needs to get the PI controller gains offline and requires accurate model so it better to use it with other controllers such as FL and Anfis.
Battery voltage by using FL and ANFIS controllers with different irradiatin levels will be illustrated in Figures $(14,15,16)$ respectivly.

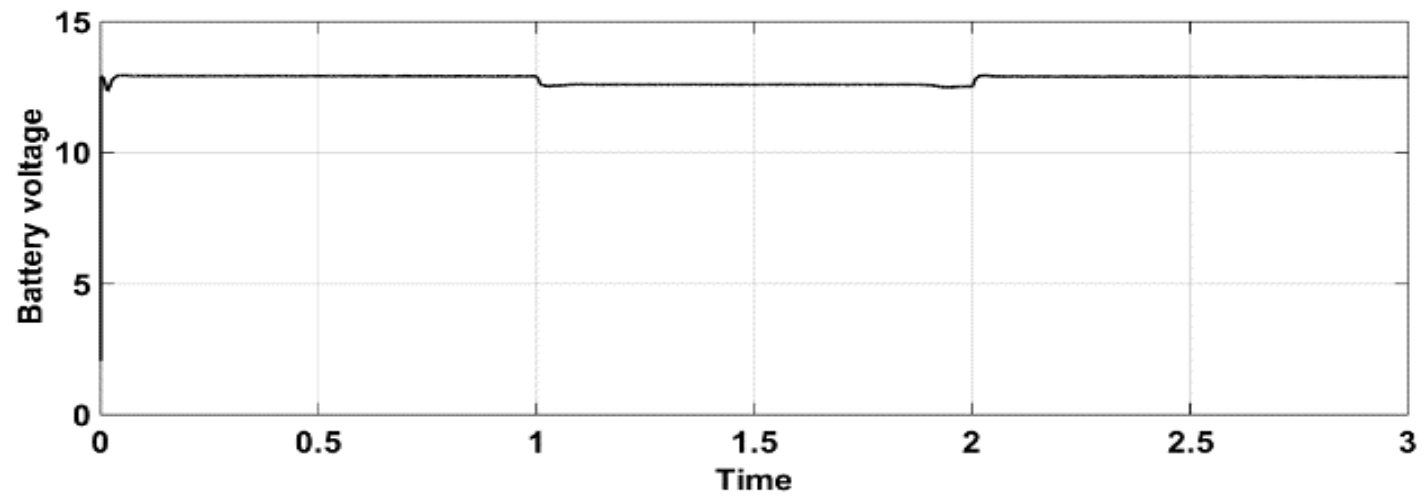

FIGURE 14: Battery charging voltage by using FL Controller

In Figure 14, battery voltage is about $13 \mathrm{~V}$ by using FL controller during battery charging and it becomes less when irradiance equals $(500) \mathrm{W} / \mathrm{m}^{2}$.

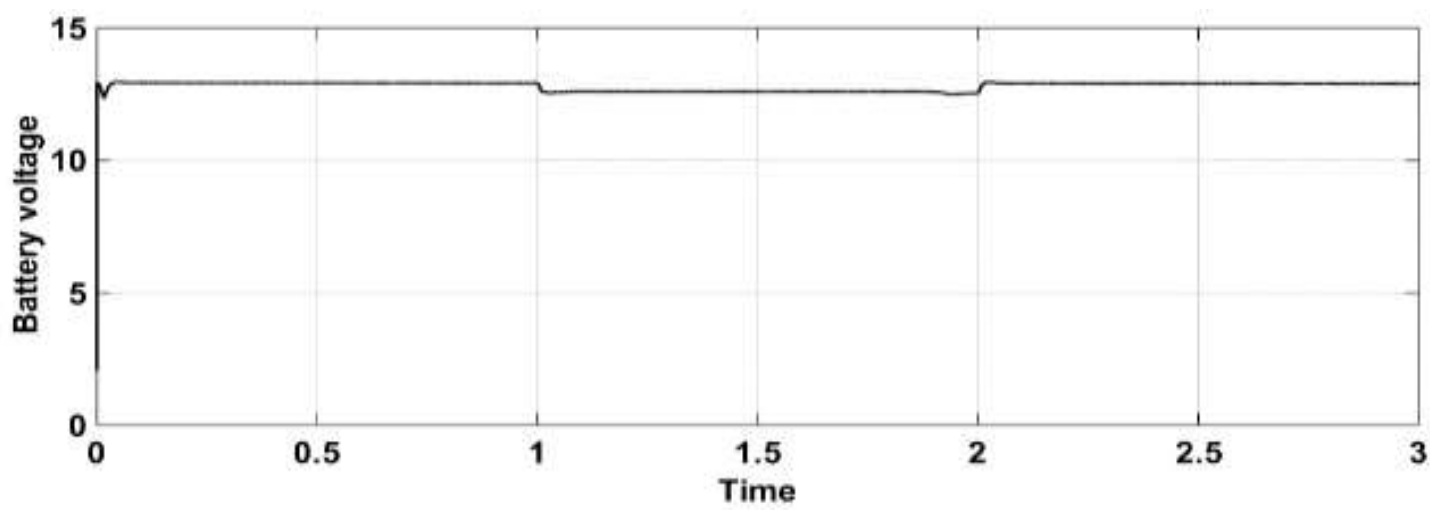

FIGURE 15: Battery charging voltage by using Anfis Controller

The MPPT output PV power using FL controller and Anfis controller methods are easier, faster and have good transient performance.

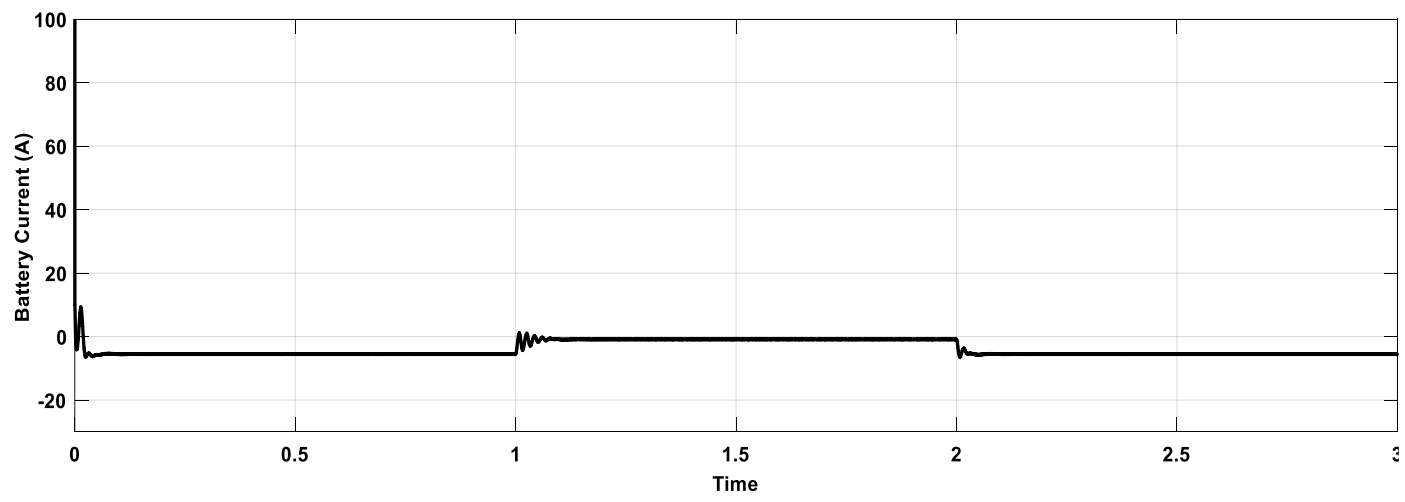

FIGURE 16: Battery charging current by using PID Controller 
Figure 16,17 show battery current and it is negative as it is during battery charging and decreases to ( -5$)$ A but it becomes more when irradiance decreases to $500 \mathrm{~W} / \mathrm{m}^{2}$ as the battery changing power becomes less.

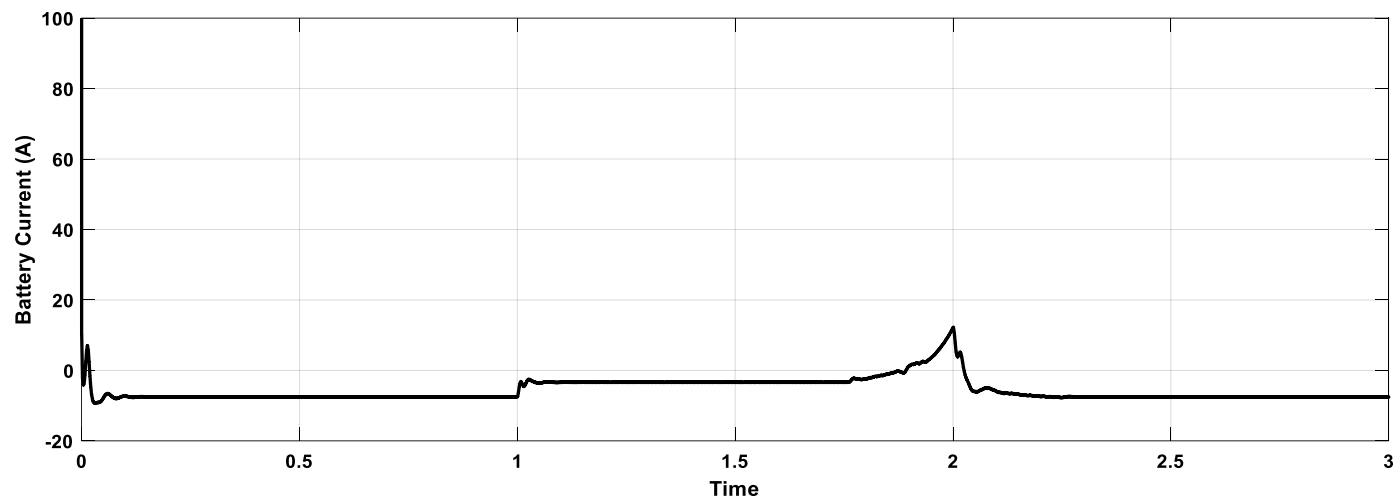

FIGURE 17: Battery charging current by using FL Controller

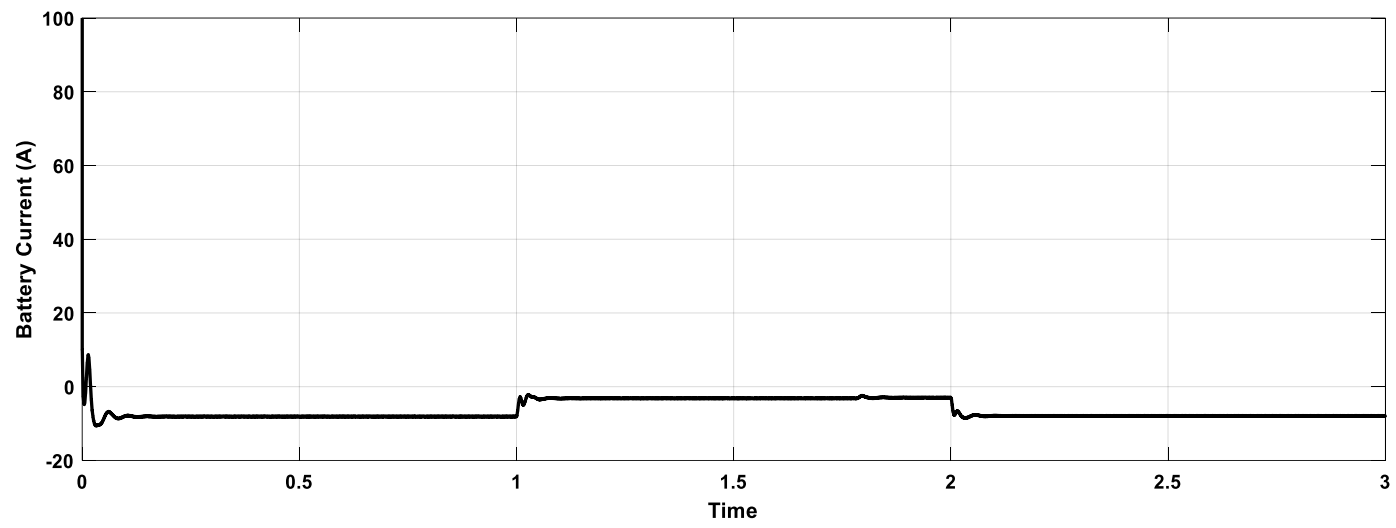

FIGURE 18: Battery charging current by using Anfis Controller

Figure 18 shows battery current and it is negative as it is during battery charging and decreases to (-7) A but it becomes more when irradiance decreases to $500 \mathrm{~W} / \mathrm{m}^{2}$ as battery changing power becomes less.

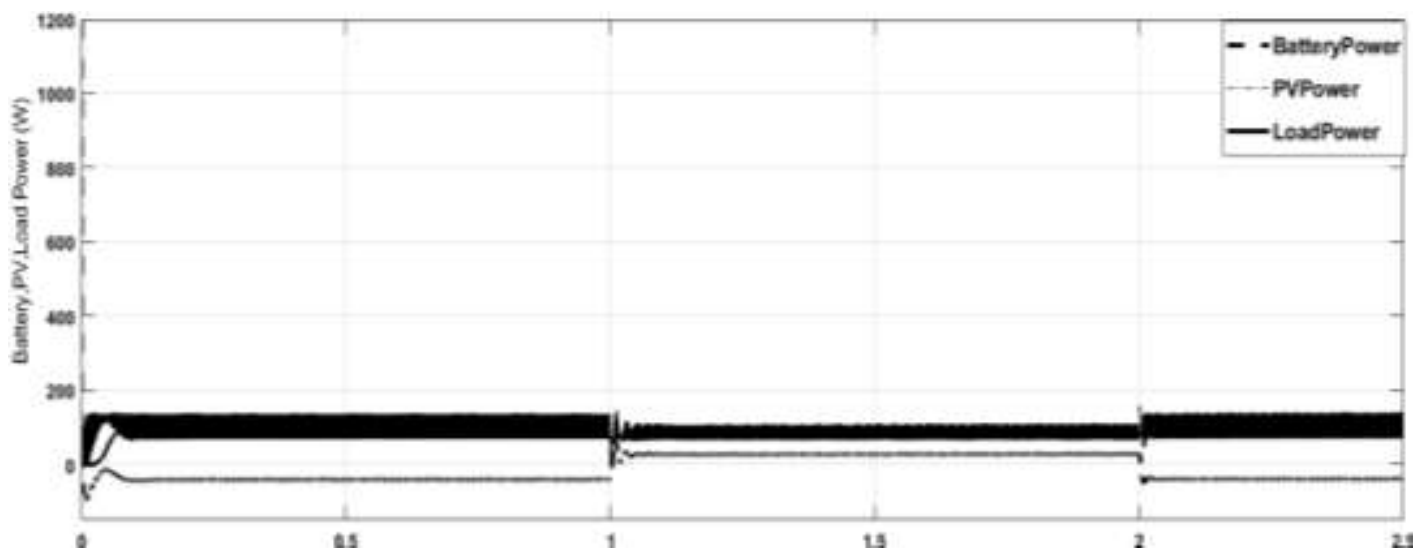

FIGURE 19: Battery, load and PV power using PID Controller

Figure 19 shows The PV power output is about $120 \mathrm{~W}$, load power is about $60 \mathrm{~W}$ and battery power decreases to $(-60) \mathrm{W}$. $\mathrm{PV}$ array power becomes less when irradiance decreases to $500 \mathrm{~W} / \mathrm{m}^{2}$ and battery changing power becomes less.

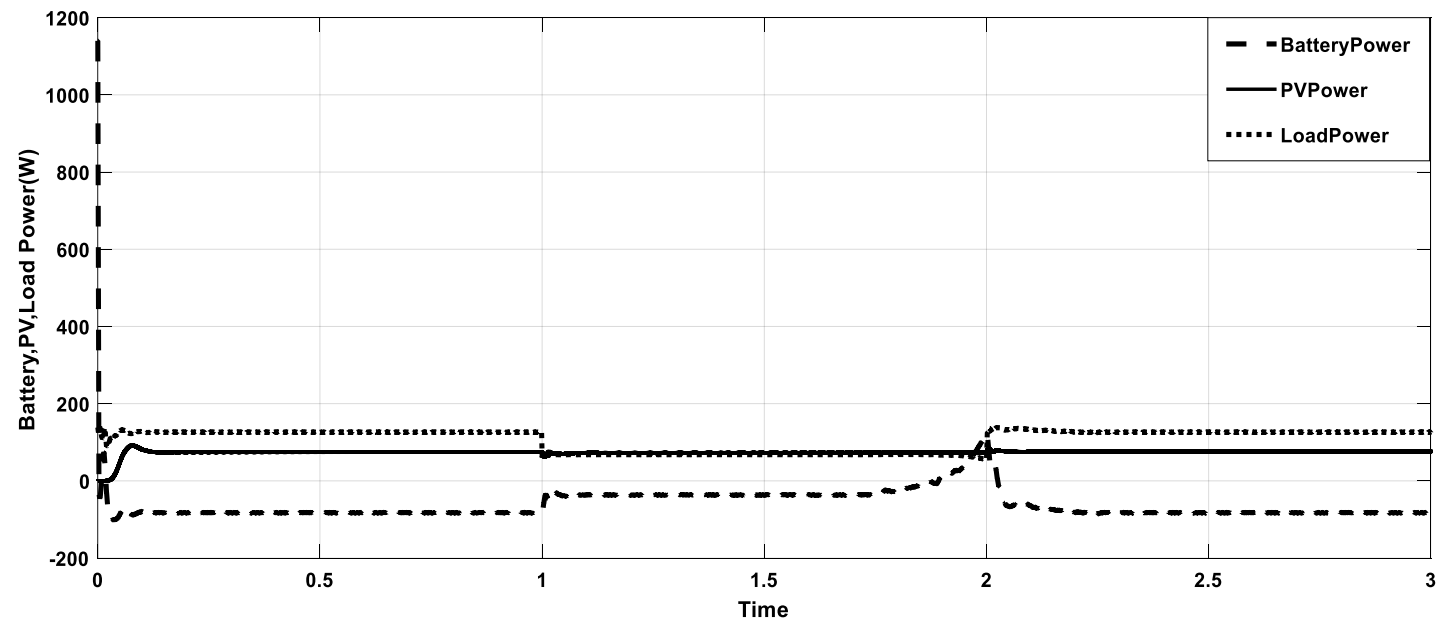

FIGURE 20: Battery, load and PV power using FL Controller 
Figure 20 shows The PV power output is about $125 \mathrm{~W}$, load power is about $60 \mathrm{~W}$ and battery power decreases to (-65) W, PV array power becomes less when irradiance decreases and battery power becomes more also.

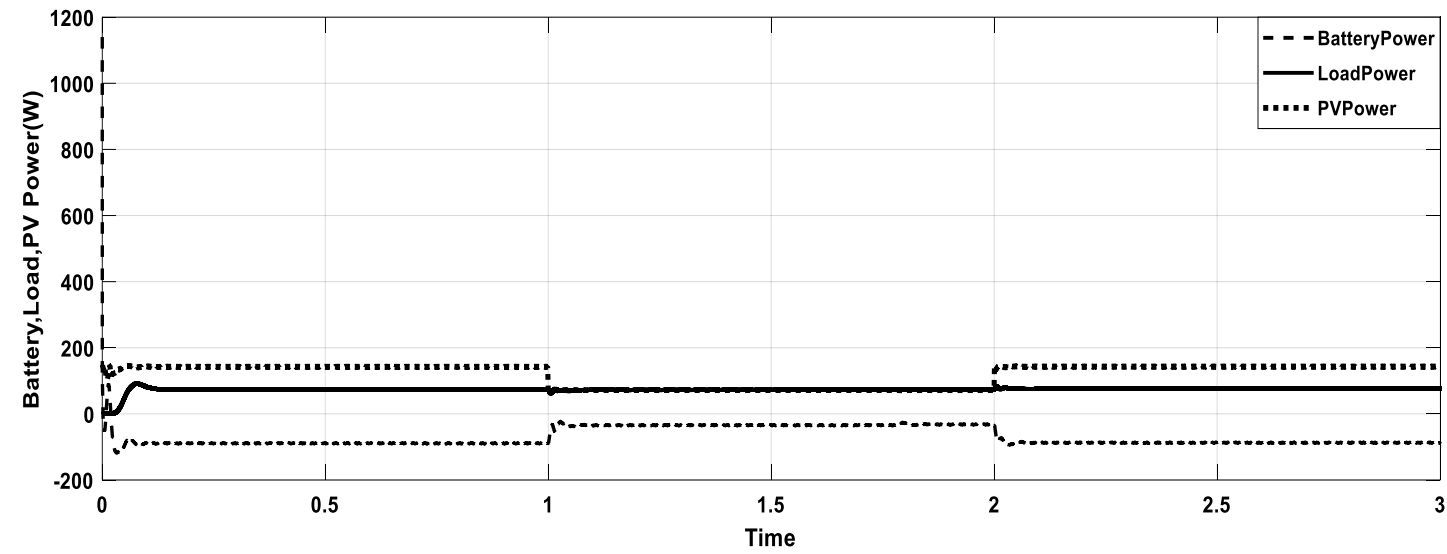

FIGURE 21: Battery, load and PV power using Anfis Controller

Figure 21 shows The PV power output is about $150 \mathrm{~W}$, load power is about $60 \mathrm{~W}$ and battery power decreases to (-90) W, $\mathrm{PV}$ array power becomes less when irradiance decreases and battery changing power becomes less.

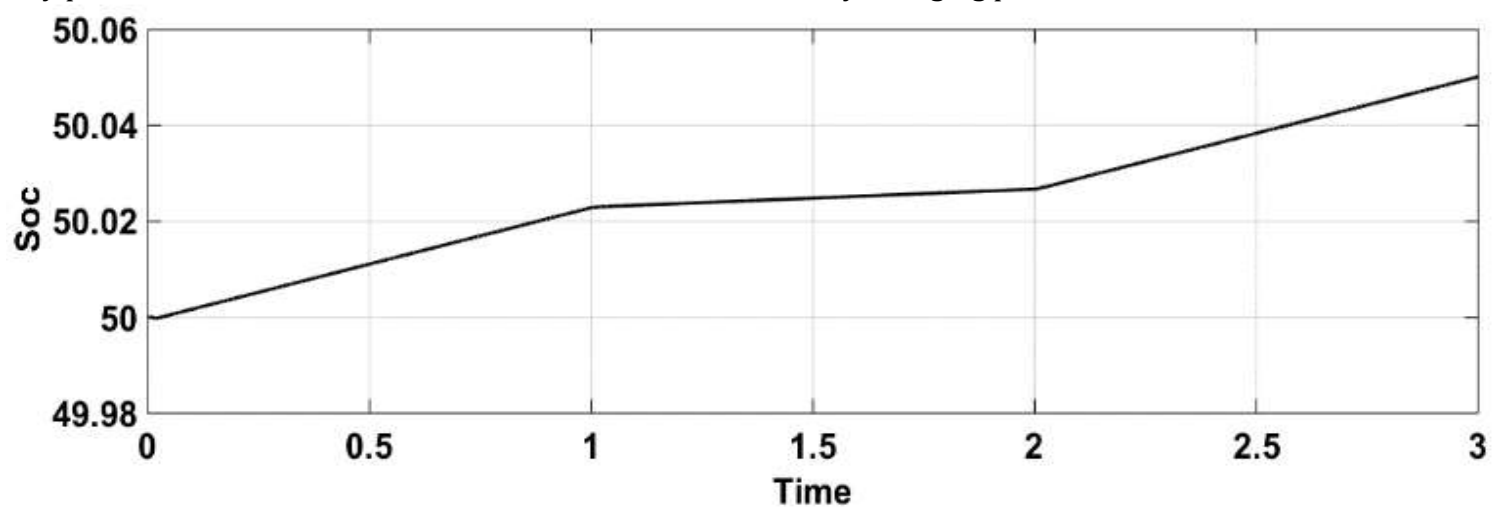

FIGURE 22: Battery Soc (\%) using PID Controller during charging

Figure 21,22,23 show Soc (\%) increases during battery charging but its slope increases more when irradiance equals 1000 $\mathrm{W} / \mathrm{m}^{2}$. By looking to these three curves, we can find that FL controller and Anfis controllers can charge the battery faster than PID controller.

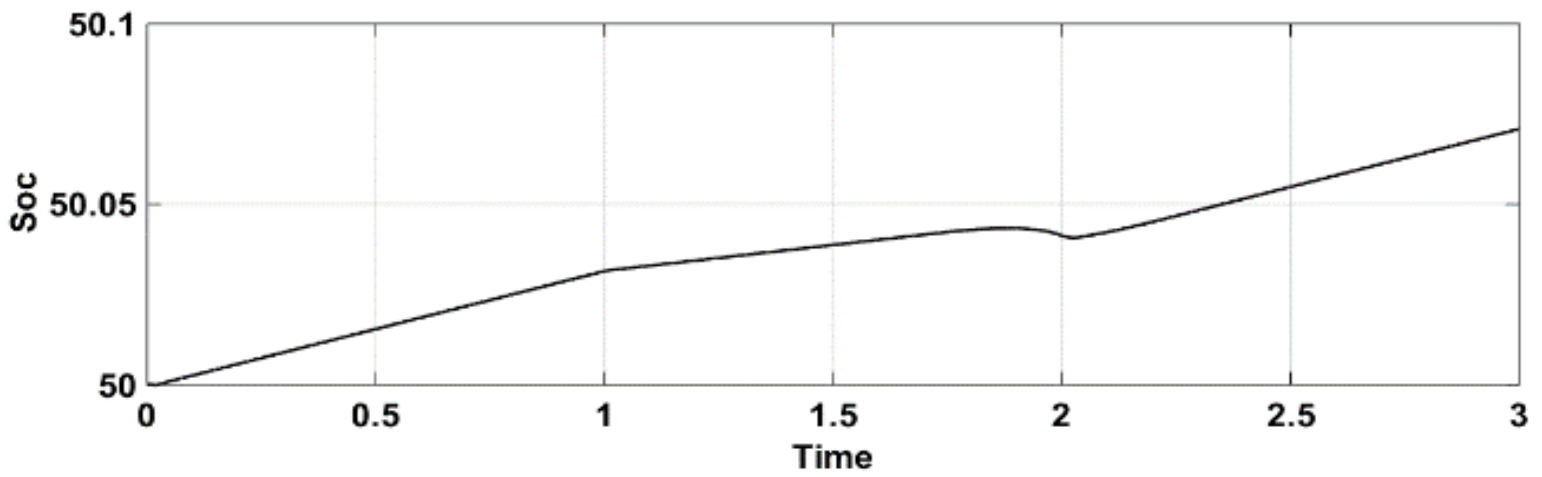

FIGURE 23: Battery Soc (\%) using FL Controller during charging

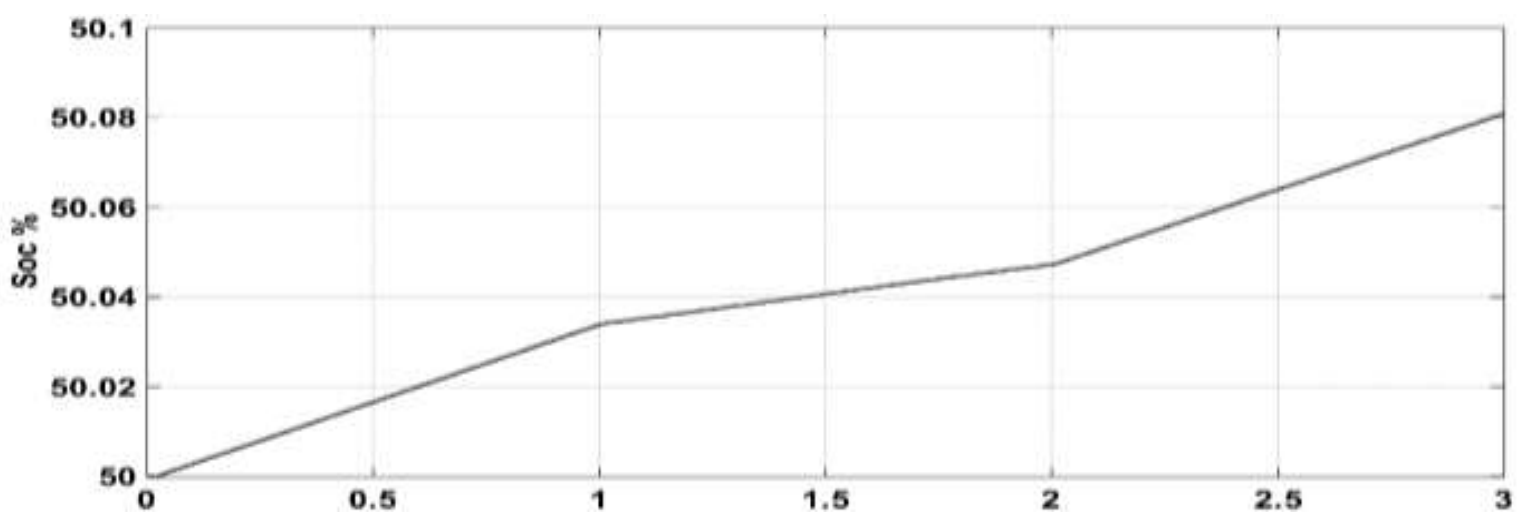

FIGURE 24: Battery Soc (\%) using Anfis Controller during charging 


\section{COMPARATIVE STUDY OF PV OUTPUT POWER FIGURES FOR MPPT CONTROLLERS}

The optimum output power of the PV system is the output of Anfis controller as we can see in Figure 25 comparing with the FL controller.

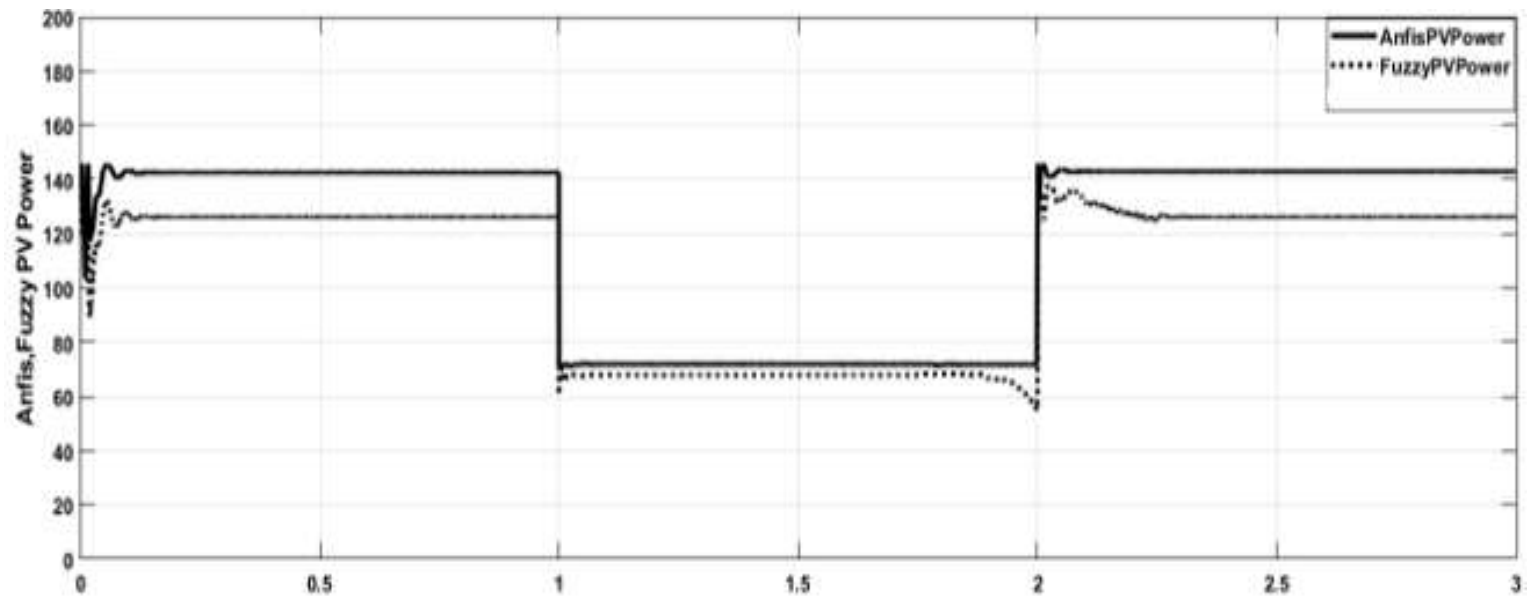

FIGURE 25: Comparison of proposed MPPT methods FL controller and Anfis controller with variable irradiance

\section{CONCLUSION}

PI controller, FLC and ANFIS based MPPT are studied and tested in MATLAB/Simulink steady state environment and they all can deliver the maximum power efficiently with the variation of solar irradiation.

Due to the various factors, temperature and solar irradiation play a vital role in deciding the PV output voltage and current. These problems are minimized using FL and Anfis algorithms in MPPT. The output power with Anfis is better than with fuzzy logic control. Generally, change in solar irradiation will cause the PV output current to change considerably but by using the neural-fuzzy algorithm in MPPT, the output power of PV module reaches MPP as the duty cycle $\mathrm{D}$ is directly proportional to the environmental changes.

\section{REFERENCES}

[1] Elkin Edilberto Henao-Bravo "Design Method of Dual Active Bridge Converters for Photovoltaic Systems with High Voltage Gain", Colombia; Published: 3 April 2020

[2] Eduardo Quiles "Accurate Sizing of Residential Stand-Alone Photovoltaic Systems Considering System Reliability", Spain, 10 February 2020

[3] A.D. Grasso, C. Sapuppo, G.M. Tina*, and R. Giusto* "MPPT charge regulator for photovoltaic stand-alone dual battery systems" DIEES-IDRILAB - University of Catania (ITALY), gtina@diees.unict.it **SIELTE, R\&D - Catania, (ITALY) 21 May 2014

[4] Rodney H.G. Tan1, *, Chee Kang Er1, and Sunil G. Solanki1," Modeling of Photovoltaic MPPT Lead Acid Battery Charge Controller for Standalone System Applications" UCSUniversity, Faculty of Engineering, Technology and Built Environment, 56000 Kuala Lumpur, Malaysia.E 3S Web of Conferences 182, 03005 (2020).

[5] Luke Farrier, "Investigating the Performance Capability of a Lithium-ion Battery System When Powering Future Pulsed Loads", UK; Published: 14 March 2020

[6] Helmut-Qualtinger, "How to make a 10kW bidirectional AC/DC converter",Vienna, May 13, 2020

[7] Prahaladh Paniyil, "Photovoltaics- and Battery-Based Power Network as Sustainable Source of Electric Power", USA; Published: 25 September 2020
[8] Charles Aimiuwu Osaretin, "DESIGN AND IMPLEMENTATION OF A SOLAR CHARGE CONTROLLER WITH VARIABLE OUTPUT"university of Benin • Benin City, Nigeria,October 2016 - July 2017

[9] Andre Susanto, Chitra Priambodo," Rooftop Solar PV System Designers and Installers"Asia Pacific Economic Cooperation Secretariat 35 Heng Mui Keng Terrace Singapore 2019

[10] Hasan Sildir "Optimization of a Fuzzy-Logic-ControlBased MPPT Algorithm Using the Particle Swarm Optimization Technique", Turkey,Published: 4 June 2015

[11] Helmy M. El_Zoghby, A.F.Bendary "A Novel Technique for Maximum Power Point Tracking of a Photovoltaic Based on Sensing of Array Current Using Adaptive Neuro-Fuzzy Inference System (ANFIS)", The 4th international conference on renewable energy generation and applications (ICREGA16), February 8-10, 2016,Belfort, France.

[12] SAMAH M. SALEEM "Maximum Power Point Tacking Techniques for Grid Connected Photovoltaic System Using Intelligent Control",7 of Jan,2021, Egypt.

[13] Abdulaziz M. S. Aldobhani," Maximum Power Point Tracking of PV System Using ANFIS Prediction and Fuzzy Logic Tracking". Proceedings of the International Multiconference of Engineers and Computer Scientists 2008, Hong Kong

[14] Jaw-Kuen Shiau "A Study on the Fuzzy-Logic-Based Solar Power MPPT Algorithms Using Different Fuzzy Input Variables" June 2015, Department of Aerospace Engineering, Tamkang University, Tamsui,Taiwan.

[15] Pressa PERDANA Surya" Review and comparison of DC-DC converters for maximum power point tracking system in standalone photovoltaic (PV) module"October 2017, Indonesia

[16] Zinab Afifi "Optimized Gentic-ANFIS Algorithm for Efficient Maximum Power Point Tracking of Photovoltaic Systems"January 2015,Banha,Egypt.

[17] Mohamed Derbeli" Article Fuzzy Logic Approach for Maximum Power Point Tracking Implemented in a Real Time Photovoltaic Systeml" System Engineering and Automation Deparment, Faculty of Engineering of Vitoria-Gasteiz, Basque Country University, Vitoria-Gasteiz, Spain;2021. 